\title{
Advances in the Production and Batch Reformatting of Phage Antibody Libraries
}

\author{
Rose H. Reader ${ }^{1} \cdot$ Robert G. Workman ${ }^{1} \cdot$ Ben C. Maddison ${ }^{2} \cdot$ Kevin C. Gough ${ }^{1}$ (i)
}

Published online: 29 August 2019

(c) The Author(s) 2019

\begin{abstract}
Phage display antibody libraries have proven an invaluable resource for the isolation of diagnostic and potentially therapeutic antibodies, the latter usually being antibody fragments converted into IgG formats. Recent advances in the production of highly diverse and functional antibody libraries are considered here, including for Fabs, scFvs and nanobodies. These advances include codon optimisation during generation of CDR diversity, improved display levels using novel signal sequences, molecular chaperones and isomerases and the use of highly stable scaffolds with relatively high expression levels. In addition, novel strategies for the batch reformatting of $\mathrm{scFv}$ and Fab phagemid libraries, derived from phage panning, into IgG formats are described. These strategies allow the screening of antibodies in the end-use format, facilitating more efficient selection of potential therapeutics.
\end{abstract}

Keywords Phage display $\cdot$ Recombinant antibody $\cdot \mathrm{scFv} \cdot \mathrm{Fab} \cdot$ Nanobody $\cdot \mathrm{V}_{\mathrm{H}} \mathrm{H} \cdot \mathrm{V}_{\mathrm{NAR}}$

\section{Introduction}

Phage display libraries based on M13 filamentous bacteriophage can present a vast diversity of antibody fragments on the pIII minor coat protein, utilising either a phagemid or phage vector system to encode the antibody-coat protein fusion (the different display systems including mutated helper phage are reviewed elsewhere, [1-3]). The presence of the antibody on the surface of the phage particle is accompanied by the gene for the antibody being packaged within

Kevin C. Gough

kevin.gough@nottingham.ac.uk

Rose H. Reader

svxrr@exmail.nottingham.ac.uk

Robert G. Workman

robworkman@hotmail.com

Ben C. Maddison

ben.maddison@adas.co.uk

1 School of Veterinary Medicine and Science, The University of Nottingham, College Rd., Sutton Bonington, Loughborough, Leicestershire LE12 5RD, UK

2 ADAS Biotechnology, School of Veterinary Medicine and Science, The University of Nottingham, College Rd., Sutton Bonington, Loughborough, Leicestershire LE12 5RD, UK the phage. In this way the phenotype (antibody binding) and the genotype (antibody gene) are linked [2]. Within standard panning methods, the highly diverse antibody library is introduced to an immobilised antigen and unbound phage washed away, bound phage are then eluted, usually by a shift in $\mathrm{pH}$ and the resulting sub-library propagated in Escherichia coli to amplify each phage clone. Such panning cycles are usually carried out 3-5 times to enrich for phage-antibodies that bind to the target antigen and hundreds of single phage clones are then isolated, propagated and tested in ELISAs [2]. More recently, screening has used next generation sequencing platforms to sequence thousands to millions of antibody genes contained within the selected sub-libraries of phage after panning. Sequencing usually targets the whole $\mathrm{VH}$ or the CDRH3 domain. These methods allow a thorough investigation of the enrichment of phage clones, even when they are minor components of the sub-libraries [4-6]. Phage display libraries can enable the identification of a variety of antibodies with desirable binding properties including antibodies that bind to toxic or non-immunogenic antigens.

Naturally occurring or designed antibody domains have been developed that are suited for phage display but still retain the binding properties of a full-length IgG (Fig. 1). These domains include antigen binding fragments (Fab), single chain $\mathrm{Fv}(\mathrm{scFv})$ and single domain antibodies 
Fig. 1 Representations of the different structures of antibodies and antibody fragments for phage display. The multidomain structure of conventional $\mathrm{IgG}$ and heavy chain antibody (camelid and shark) (a). Antibody fragments can be displayed on phage as Fabs, scFvs or nanobodies $\left(\mathrm{V}_{\mathrm{H}} \mathrm{Hs}\right.$ or $\mathrm{V}_{\mathrm{NAR}}$, derived from camelid or shark, respectively). The synthetic scFab-Fc dimer is also shown (b). $V$ variable domain, $C$ constant domain, $H$ heavy chain, $L$ light chain
A

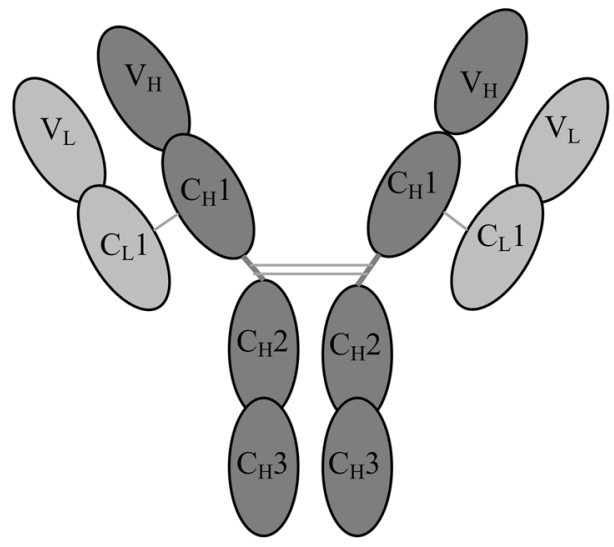

IgG

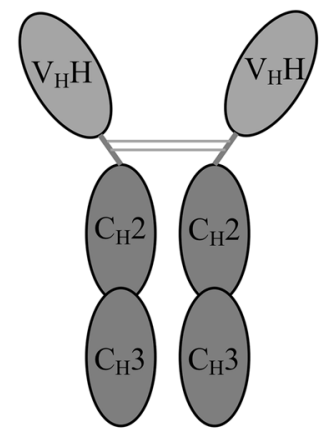

Camelid HCAb

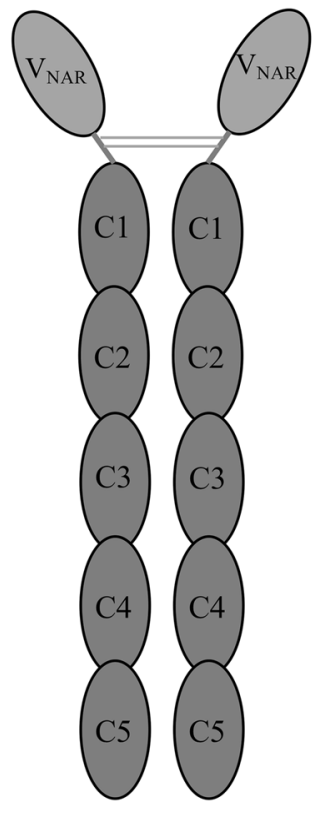

Shark $\mathrm{HCAb}$

B

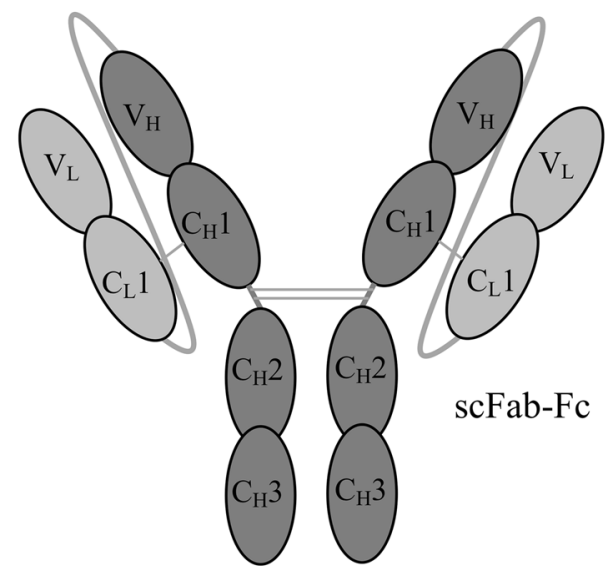

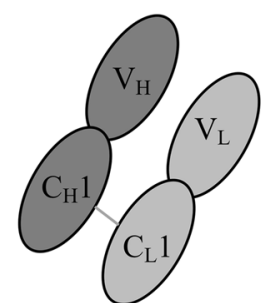

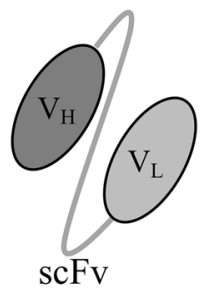

$\mathrm{Fab}$
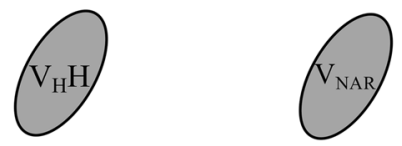

$\mathrm{V}_{\mathrm{H}} \mathrm{H}$

$\mathrm{V}_{\mathrm{NAR}}$ (nanobodies). The latter include camelid $\mathrm{V}_{\mathrm{H}} \mathrm{H}$ and shark $\mathrm{V}_{\mathrm{NAR}}$ (New Antigen Receptor).

Phage antibody libraries are classed as naïve, semisynthetic, synthetic or immune libraries [2]. The latter are produced by cloning the antibody genes from immunised animals (e.g. [7-9]) or diseased or vaccinated humans [10, 11] and are directed towards a single or limited number of antigens. Naïve phage display libraries are produced from the natural antibody repertoire of donors. Alternatively, phage display libraries can be produced using a relatively small diversity of natural antibody sequences whose diversity is increased through mutating one or more complementarity determining regions (CDRs) (semi-synthetic libraries). Libraries can also be based on a single or very low number of "scaffold" sequences with introduced diversity in the CDRs (synthetic libraries). Immune libraries require 
immunisation and library cloning for each antigen but small repertoire libraries $\left(\sim 10^{6}\right)$ usually facilitate the isolation of high affinity binders (e.g. [7-9]). On the other hand, naïve or synthetic/semi-synthetic libraries (collectively known as single-pot libraries) can be used against any antigen but are required to have very high diversity (typically $>10^{10}$ ) to allow the isolation of high affinity binders (e.g. [12-16]).

In terms of antibody formats, Fabs consist of the VH-CH1 and VL-CL chains, one of which is fused to the PIII protein [17]. In phage display systems these two chains are usually expressed separately and assemble into the Fab format within the periplasm of the bacteria via a disulphide bond linkage. ScFvs consist of just the VH and VL chains joined together by a peptide linker with one chain fused to the pIII protein [12]. This single chain is expressed and targeted to the periplasm where the $\mathrm{scFv}$ folds into its active conformation. Nanobodies are an alternative antibody fragment and at just $12-15 \mathrm{kDa}$ are smaller than Fabs or scFvs. They are derived from natural heavy chain antibodies found in camelids and sharks that lack a light chain (Fig. 1a). Nanobodies consist of the equivalent of a conventional IgG VH domain and again can be fused to the pIII phage protein for display $[18,19]$.

Examples of all of these antibody types with high specificity and affinities in the low $\mathrm{nM}$ to $\mathrm{pM}$ range have been directly selected by phage display (Table 1 ). A consideration when developing a single-pot antibody phage display system is that a high diversity will be more likely to deliver the best binders and the higher the level of display the more effective the selection of these binders will be. High specificity and affinities enable them to be effective in their applications such as for drug delivery, therapeutics, in vivo imaging or diagnostic assays. Recombinant antibody fragments are relatively small and lack an Fc domain. Considering in vivo applications, these properties may have advantages where high tumour/tissue penetration and a short half-life are advantageous, such as for in vivo imaging [20, 21]. In contrast, most protein therapeutics are based on human/ humanised antibody fragments that are converted into larger antibody structures such as IgG. A strategy designed to minimise immunogenicity, elicit effector functions and extend serum half-life [22]. The use of recombinant antibodies as therapeutics is of increasing importance. In a review in 2016, Frenzel et al. reported that there were 64 phage display derived antibodies or antibody conjugates that had undergone some stage of clinical trials and the vast majority of these antibody fragments had been converted to IgG or IgGconjugate formats [23]. A more recent update in 2019 stated that over 80 phage display derived antibodies had entered clinical studies and more than 10 had marketing approval [24].

This review will consider recent advances in the cloning and functional display of antibody libraries, as well as their batch reformatting into IgG-like molecules.

\section{Antigen Binding Fragment (Fab)}

Fabs were one of the first type of recombinant antibody that was produced as a diverse repertoire displayed on the surface of bacteriophage, first being described in 1991 [17]. As mentioned above, antibodies will usually be required to have high specificity and affinity and therapeutic applications may require the antibody to be converted into an IgG format. Ideally, this reformatting would be done before the screening of antibodies resulting from phage display panning as the binding properties of the monovalent Fab will be different from the divalent IgG [21, 25, 26]. In addition, high expression levels and high stability of Fab and $\mathrm{IgG}$ are vital to produce useful reagents [25].

There have been several recent reports on the production of Fab phage display libraries with either simplified cloning strategies or improved/distinct diversity. Typically, the light chain VL-CL gene will be expressed separately from the VH-CH1-pIII fusion gene. Both proteins are targeted to the periplasm where they interact to form a Fab-pIII fusion that is then packaged into assembling phage.

Type II restriction enzymes have been used in a so-called 'seamless' cloning strategy for Fabs. After screening human, rabbit and mouse antibody gene repertoires, enzymes were selected that either did not cut or cut very infrequently in antibody gene sequences. Appropriate phagemid vectors were then produced including these restriction enzyme cleavage sites for the cloning of human (using BsmBI and
Table 1 Comparing high affinity ligand types that can be used in phage display

\begin{tabular}{llll}
\hline Ligand type & $\sim$ Size $(\mathrm{kDa})$ & $\begin{array}{l}\text { Typical affinity range } \\
\text { of selected clones* }\end{array}$ & Reference examples \\
\hline Antigen binding fragment (Fab) & 55 & $\mathrm{nM}-\mathrm{pM}$ & {$[29,100]$} \\
Single chain variable fragment $(\mathrm{scFv})$ & 25 & $\mathrm{nM}-\mathrm{pM}$ & {$[12,35]$} \\
$\mathrm{V}_{\mathrm{H}} \mathrm{H}$ & 15 & $\mathrm{nM}-\mathrm{pM}$ & {$[101,102]$} \\
Shark $\mathrm{V}_{\mathrm{NAR}}$ & 12 & $\mathrm{nM}$ & {$[19,90]$} \\
Human VH or VL single domain antibodies & 15 & $\mu \mathrm{M}-\mathrm{nM}$ & {$[64-66]$} \\
\hline
\end{tabular}

*Before affinity maturation 
SapI, vector pUP-22Hb), rabbit (SapI only, vector pUP22Rc) and mouse (SapI, vector pUP-22Mc) Fabs, and libraries of diversities $\sim 10^{9}$ produced [27]. These libraries only use kappa light chains and this strategy clones amplicons of VH and VL into the vector in a single step. Whilst this was applied to produce immune libraries only (the human library was a mouse/human chimeric library), the repertoire achieved for the libraries demonstrates the strategy is applicable to produce more diverse single-pot Fab libraries.

It has been reported that rabbit B cell repertoires may be very different to those of human or mice due to the unique ontogeny of rabbit B cells and extensive somatic gene conversion [28]. Peng et al. [29], recently produced a naïve rabbit/human chimeric Fab library of $\sim 10^{10}$ diversity made up of rabbit $\mathrm{VH} / \mathrm{VL}$ regions and human $\mathrm{CH} 1$ and $\mathrm{CL}$ domains. The strategy used multiple step wise PCR amplifications of the VH and VL genes for use as part of the templates in a 3-fragment overlap extension PCR to amplify VL-CLVH for Kappa and Lambda light chains, and the subsequent cloning of the products into a $\mathrm{CH} 1$ containing vector. The study selected a range of antibodies with high specificity and affinities in the low $\mathrm{nM}$ range.

When synthetic diversity is added into libraries it is usually targeted at the CDRH3 and CDRL3 domains as they are reported to have the greatest influence on specificity and affinity [30]. One recently produced library used the scaffold Fab Hu4D5-8 that has high thermal stability. Limited diversity was introduced into the CDR1 and CDR2 of both heavy and light chains with sequences matching the most canonical CDR conformations in the scaffold sequence. High random sequence diversity was then introduced into CDR3s (7-25 residues) to produce a library repertoire of $7 \times 10^{9}$. The strategy also used a previously described bivalent display of Fabs which are displayed in a Fab-GCN4 leucine zipper-pIII display format and includes intermolecular disulphide bond sites [31]. Fabs were isolated with $\sim 2 \mathrm{nM}$ affinities.

There are several commercially available Fab libraries, for example the Ylanthia library from MorphoSys [30]. This library has very high diversity and is based on 36 fixed heavy/light chain pairs selected from 400 combinations that were characterised for desirable biophysical properties. These were relatively high expression in bacteria and mammalian cells as Fabs or IgG, respectively, high display levels on phage, high thermal stability and low aggregation in both Fab and IgG formats. CDRH1 and CDRH2 had limited diversity introduced to remove sites for post-translational modifications (PTM). High diversity was then introduced into CDRH3 and CDRL3, again avoiding PTM sites, to produce a library of $10^{11}$ clones. One clone selected by panning had an affinity of $700 \mathrm{pM}$. A range of clones gave yields ranging from $1.5-13 \mathrm{mg} / \mathrm{L}$ and when converted into $\mathrm{IgG}$ and transiently expressed in HKB11 cells, $20-80 \mathrm{mg} / \mathrm{L} \mathrm{IgG}$ was produced.
Stability of the Fab and concomitant IgG is an important factor in library design and can be addressed as above by selecting scaffold Fab structures with high thermostability. An alternative approach isolated thermostable scaffolds by transiently heating a Fab phage library before selection of functional Fabs with an anti-light chain antibody [32]. Five unique Fabs were identified and each had increased stability. Combinations of the Fabs' mutations resulted in an optimal triple mutant with high stability that also translated into a similarly highly stable IgG. It was speculated that the CDRH1 region mediated this increase in stability.

Insufficient solubility can often lead to candidate antibodies not being fully developed for diagnostic or therapeutic applications. In silico programmes that can predict antibody solubility have been applied to Fabs that have been converted into IgGs. The predictions from these in silico programmes have been compared to a range of in vitro tests for protein aggregation, stability and solubility [33]. Seventeen antibody variants with a wide range of predicted solubilities were characterised and the in silico prediction tools displayed significant correlation with the in vitro test. The authors concluded that the CamSol programme could be used to efficiently identify lead antibodies to take forward for development. This provides a rapid and cost-effective method for improved selection of lead antibodies. Such in silico stability prediction tools may also have application to the design of a high solubility Fab scaffold for synthetic library production. Whilst the selection of such a scaffold may help facilitate the selection of high solubility reagents, this may be limited by the mutated CDR regions making significant contributions to the solubility of the Fabs. Postpanning solubility testing will therefore still be required.

Fabs are often reported as having relatively low phage display levels compared to scFvs, which may be attributed to their relatively complex disulphide bond formation [26, 34]. Several recent studies have looked to improve Fab display levels. Huovinen et al. [35] compared the panning enrichment of the same Fab repertoire on pIII (rescued with wild type helper phage or hyperphage), truncated pIII and pIX (a minor coat with $\sim 5$ copies per phage particle, the same as for pIII). They also compared scFv displayed on truncated pIII. Fab displayed on pIX had the lowest selection efficiency, the highest diversity of clones was obtained with Fab or scFvs displayed on truncated pIII. Increasing the display valency with hyperphage improved the selected clone diversity. It was shown that a single propagation of phage resulted in large reductions in diversity of antibodies for the Fab-pIII and scFv-truncated pIII libraries, where frameshift mutations seemed to be selected for. The study indicated that the optimal display of Fabs was on truncated PIII and this may be further improved by increasing Fab valency using hyperphage. 
The use of co-expression of molecular chaperones or isomerases to improve Fab folding/stability and export into the periplasm has also recently been reported. For example, co-plasmid expression of $D s b A, D s b C, F k p A$ and SurA has been used. The expression of the peptidyl prolyl cis-trans isomerases (PPIases) FkpA and SurA directed to the periplasm may improve folding, and $D s b A$ and $D s b C$ help optimise disulphide bond formation [34]. The selection of Fabs during panning was greatly improved with much higher levels of Fab detected on phage through each round of panning compared to when the co-plasmid was not present. A study by Levy et al. [36] also used co-expression of the PPIase $F k p A$, but it was retained in the cytoplasm or directed to the periplasm. Functional Fab levels were improved to a greater extent when the $F k p A$ was expressed in the cytoplasm. During panning, the system improved the diversity of antigen specific Fabs from 10-16\% to 43-48\%. The authors speculate that $F k p A$ isomerises proline residues in kappa light chains and when subsequently exported to the periplasm this improved folding and Fab assembly. The strategy improved periplasmic soluble Fab levels from $0.4-2.5 \mathrm{mg} / \mathrm{L}$ to $3.5-14.2 \mathrm{mg} / \mathrm{L}$.

A different approach displayed single chain Fabs (scFab) where the $\mathrm{C}$-terminal of the light chain was linked via an extended 60 amino acid linker to the $\mathrm{N}$-terminus of the heavy chain [25]. This extended linker allowed retention of the interchain disulphide bond (shorter linkers necessitated the removal of this bond) and effective scFab display. The authors speculated that this approach of tethering of the Fab chains may increase the folding rate. The study also looked at optimising the secretion of the Fabs by routing through the signal recognition particle (SRP) pathway for co-translational secretion and comparing this to the more usually employed secretion of the unfolded post translation scFab proteins. The former used the signal sequence from $D s b A$ and the latter the pelB signal sequence. The hypothesis was that co-translational secretion would prevent any scFab folding in the cytoplasm that may reduce efficient folding/secretion. In addition, the study also selected optimised mutants of the signal peptides and found 3 mutants of pelB and 2 of the $D s b A$ signal sequence with improved display levels. Overall, using an optimised $D s b A$ signal sequence resulted in a threefold improvement in display to $0.5 \mathrm{scFabs} / \mathrm{phage}$ particle. In terms of scFab expression levels, soluble scFab was improved from 1-3 mg/L to $3-4 \mathrm{mg} / \mathrm{L}$ when switching to the co-translational secretion system.

It is often desired to convert Fabs into full-length IgGs as the final antibody reagent. This is often not a straight forward procedure and usually takes 2 steps, each of which sequentially clones the $\mathrm{VH}$ and $\mathrm{VL}$ (or whole light chain) domains into an expression vector. Either using a single expression vector (Fig. 2a) or more usually by cloning the light and heavy chain domains into distinct vectors [37]. As these conventional reformatting strategies clone the heavy and light chain variable regions independently they are unsuitable for batch cloning, where heavy and light chains would need to retain their pairing. Screening recombinant antibodies from phage display in an $\mathrm{IgG}$ format is therefore labour intensive and presents a bottleneck in discovering functional IgGs [37]. Jostock et al. [21] reported vectors that could express Fabs as human IgG1 or IgG4 or mouse IgG2a antibodies. These also allowed Fab regions to be switched between vectors. The cloning strategy retained the pairing of light and heavy chain regions and so could be applied to the batch cloning of Fabs from phagemid into the $\mathrm{IgG}$ expression vectors. The method readily recovered $~ 90 \%$ of the Fabs, allowing screening to be done with divalent IgGs produced in mammalian cell culture (see Fig. $2 b$ for cloning details). Transient expression in HEK293T cells produced 5-18 mg/L IgG. An alternative approach has been described that uses a vector (pDV) that is compatible with both bacterial expression of Fab and mammalian cell expression of full-length heavy chain without sub-cloning [26] (see Fig. $2 \mathrm{c}$ for cloning details). Fab diversity was only within the heavy chain in the pDV library. The system was based on a signal sequence from murine binding immunoglobulin protein (mBIP) that can support secretion of heavy chain sequences in both cell types. A stop codon after the pIII protein prevents the expression of the Fc region within bacteria. The pIII gene and stop codon were sited within an intron and were removed by RNA splicing in mammalian cells allowing expression of full-length heavy chain. Within the mammalian cells an invariable light chain was expressed from a separate vector to allow IgG formation. A library of $10^{9}$ diversity was produced and panning allowed selection of specific Fabs. Cognate IgGs were transiently expressed and several had affinities in the low nM range. The levels of $\mathrm{IgG}$ produced were $2-6 \mathrm{mg} / \mathrm{L}$ which is lower than with other expression vector systems but was sufficient for screening antibodies. Alternatively, the scFab system described by Koerber et al. [25] allowed batch cloning in a single step to an scFab-Fc format (scIgG; see Fig. 2d for details), made up of IL2 signal peptide-scFab-rabbit Fc. Transient expression in HEK293T cells yielded $5 \mathrm{mg} / \mathrm{L} \mathrm{scIgG.}$

\section{Single Chain Variable Fragments (scFv)}

ScFvs offer high sensitivity, specificity and ease of expression in different systems. Unlike Fabs, scFvs are expressed from a single gene and the variable regions are tethered by a flexible linker, improving both expression and refolding/ assembly [38]. However, they can display lower affinity than the corresponding Fab and can have lower long-term stability [39]. The production and utility of scFv-phage libraries and the screening and application of the binders have 


\section{A Conventional 2-step cloning of a Fab/scFv into an IgG}

$\mathrm{Fab}$
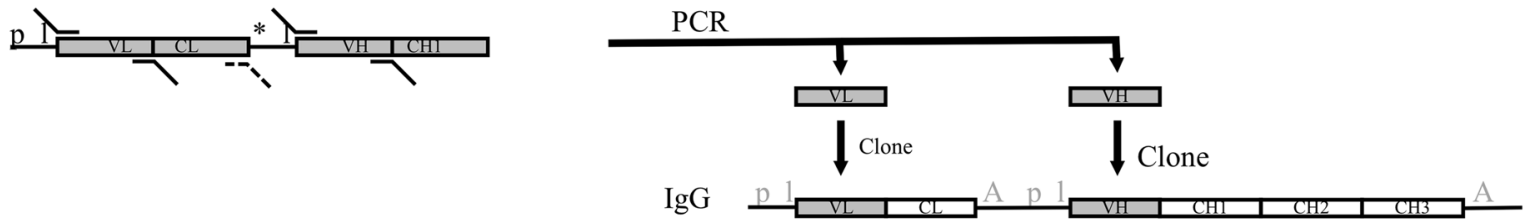

\section{B Cloning Fab into IgG maintaining LC-HC pairing}

Fab

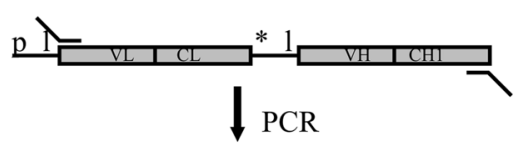

$\mathrm{Fab}$

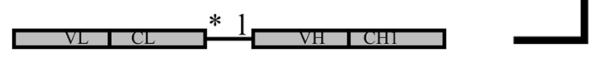

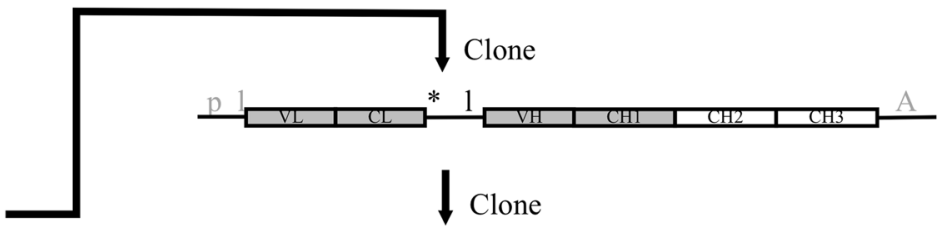

$\operatorname{IgG}$

\section{A dual expression vector for Fab/IgG expression (pDV)}

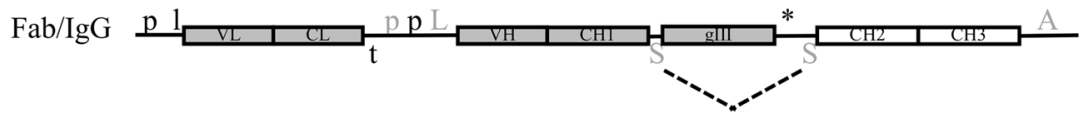

\section{Cloning of single-chain Fabs to scFab-Fc}
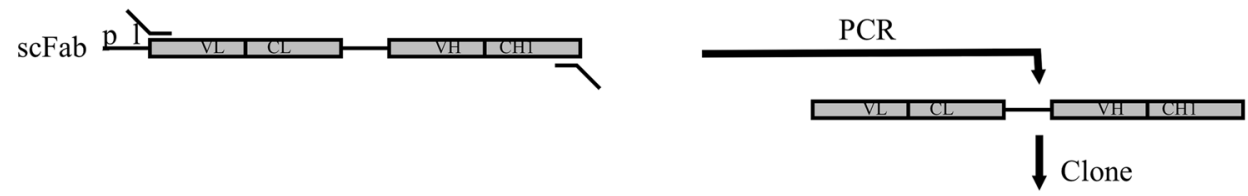

scFab-Fc

Fig. 2 A summary of key elements within different strategies to produce full-length IgG or Fc-fusion constructs from Fab phage display vectors. Conventional cloning of Fab usually includes the amplification of the $\mathrm{VH}$ and $\mathrm{VL}$ domains and cloning into appropriate sites within an ' $\mathrm{IgG}$ cassette' that contains the $\mathrm{CL}$ and $\mathrm{CH} 1, \mathrm{CH} 2$ and $\mathrm{CH} 3$ domains within a mammalian expression vector (a). For Fabs, an analogous 2 step cloning method can be used to clone the entire light chain along with the VH domain (A, dashed primer would be used). The phagemid (left hand side) will contain E. coli promoter (p) and leader (1) sequences for the expression of the Fab. The antibody fragment gene is expressed as a fusion with a downstream gIII phage coat protein gene. Once the VL (or light chain) and VH domains are cloned into the $\mathrm{IgG}$ expression plasmid, the light and heavy chains are expressed separately with their own eukaryotic promoter (p) and leader (l) sequences and poly(A) tail (A) [mammalian regulatory elements are indicated in grey font]. Fabs have also been cloned from a phagemid vector in two steps into a mammalian expression vector to retain the pairing of the light chain and $\mathrm{VH}-\mathrm{CH} 1$ domains, allowing batch cloning of polyclonal phagemid [21] (b). In the first step the Fab is amplified and cloned into the vector and then in a second

the same issues as outlined for Fabs. High diversity singlepot libraries are required to produce high affinity reagents against any target [40] and numerous libraries containing step the mammalian regulatory elements are introduced between the light chain and heavy chain genes. With a Fab library that only contain heavy chain diversity, this can be expressed within Fab or full-length $\mathrm{IgG}$ formats from the same vector (c). The pDV system [24] expresses the Fab or IgG when in E. coli or mammalian cells, respectively, without any requirement for sub-cloning steps. The construct uses a bacterial $p$ and 1 for the light chain and has a bacterial transcription terminator $(t)$ after the light chain. The sequence upstream of the $\mathrm{VH}-\mathrm{CH} 1$ genes contains bacterial and eukaryotic promoters along with a leader sequence that functions in either host cell (L). Downstream of the gIII gene is a stop codon (*) followed by a splice domain (S). A second $\mathrm{S}$ is present between the $\mathrm{CH} 1$ and gIII domains. In bacteria, Fab-gIII is expressed and in mammalian cells, intron splicing (dashed lines) removes the gIII region and the heavy chain is expressed and paired with an invariant light chain derived from a different vector. Alternatively, single chain Fabs expressed as fusions with pIII can be sub-cloned in a single step into a mammalian expression vector containing the Fc domain to make scFab-Fc [25] (d)

greater than 10 billion clones have been reported [41-43]. Consistent, high stability and high expression levels in both bacteria and mammalian systems for all library clones would 
be a valuable trait to allow the isolation and development of the best binders. As with Fabs, scFvs have relatively high tumour penetration compared to $\operatorname{IgG}$ and a rapid in vivo clearance, making them useful tools for in vivo imaging [44-46]. However, many applications require divalency and $\mathrm{Fc}$ region availability, and so the batch reformatting of scFvs into IgGs or scFv-Fc formats for screening would be of value [40].

For scFvs it has been reported that the contribution of the distinct domains to the antigen binding site is in the order $\mathrm{CDRH} 3>\mathrm{CDRH} 2>\mathrm{CDRL} 3>\mathrm{CDRH} 1>\mathrm{CDRL} 1>\mathrm{CDRL} 2$ $>$ Framework regions [40]. Naïve libraries are traditional ly produced by sequential amplification and cloning of the VL and VH regions into a phagemid vector separated by a (Gly4-Ser)3 linker [47]. They usually then contain c-myc and polyHis tags between the $\mathrm{C}$-terminus of the $\mathrm{scFv}$ and the N-terminus of the pIII coat protein. Kugler et al. [43] demonstrated that the order of the tags can influence soluble $\mathrm{scFv}$ expression levels in bacteria. They reported yields in the low $\mathrm{mg} / \mathrm{L}$ range which is similar to those produced after sub-cloning of scFvs into a pET expression vector [48]. As CDRH3 has the highest natural diversity and contributes the most to the antigen binding site [40], synthetic and semisynthetic libraries invariably target this region for mutagenesis, sometimes along with other CDRs. For example, the Tomlinson I and $\mathrm{J}$ library mutated CDR2 and CDR3 regions of both VL and VH [13], the HuCal scFv library mutated CDR3s and the HuCal GOLD library introduced diversity into all CDRs [14-16].

$\mathrm{ScFv}$ libraries are usually produced using multiple PCR reactions to amplify diversity and introduce the linker region and then assembly of scFv chains via overlap extension PCR. However, this can result in mis-annealing, particularly in the linker repeat region, and produce non-functional fragments. Nishi et al. [49] used this method to produce a synthetic library with randomised CDR3s which had a diversity of $\sim 10^{8}$ but 8 out of the 13 clones sequenced had errors. Libraries of diversity $\sim 10^{11}$ made by an analogous method contained $66-85 \%$ clones with ORFs and 58-85\% expressed soluble protein [40]. An alternative method introduced diversity through PCR and cloning of the VH and VL libraries separately into a pUC vector along with partial linker sequences containing a unique restriction site. This is then followed by sub-cloning of the libraries into a phagemid vector to form $\mathrm{scFv}$ cassettes without further PCR amplification. This strategy produced much higher levels of functional scFvs, with no errors found in 83 sequenced clones [49].

Weber et al. [50] used single VH and single VL kappa and VL lambda genes as the scaffolds for a synthetic scFv library where they introduced mutations into CDR3s with partially degenerate primers. They also chose asparagine at residue 52 of $\mathrm{VH}$ as this mutation is often present due to somatic hypermutation and during affinity maturation. The $\mathrm{VH}$ selected as scaffold had high thermal stability and also bound protein A when part of an scFv. The resulting PHILODiamond library had $\sim 10^{10}$ diversity with $90 \%$ of clones having a functional scFv. They speculated that as only the CDR3s were mutated, affinity maturation of clones could be carried out by introducing diversity into the CDR 1 and 2 loops.

Codon usage for mutagenesis in synthetic or semi-synthetic libraries is often NNN or NNK but can also be more tailored such as the use of NWG, NWC and NSG codons (where $\mathrm{N}=\mathrm{A} / \mathrm{T} / \mathrm{G} / \mathrm{C}, \mathrm{K}=\mathrm{G} / \mathrm{T}, \mathrm{W}=\mathrm{A} / \mathrm{T}, \mathrm{S}=\mathrm{G} / \mathrm{C}$ ) to avoid the introduction of cysteines and stop codons (other than amber) into CDRs [51]. Säll et al. [52] introduced an even more specific mutagenesis strategy. They used trimer phosphoramidite codons to predetermine the diversity introduced into and adjacent to CDRHs and CDRL3. The strategy introduced up to 13 amino acids into any one position and was based on the diversity of commonly found residues in natural repertoires, with particular bias for tyrosine, glycine and serine residues. The strategy also varied the length of the CDR3s. The library used single human scaffold VH and VLs (kappa and lambda) with codon optimisation for expression in bacteria and mammalian cells. Two libraries were produced, HelL-11 and then HelL-13 with diversities of $\sim 10^{10}$. The former library had stop codons in both CDR3s of the scaffold scFv and the resulting library displayed just $47 \%$ functional scFvs, it was also found that tryptophan was overrepresented within the diversity regions relative to the concomitant codon usage in the oligonucleotide synthesis. The HelL-13 library was adjusted to remove tryptophan bias and also used a scaffold scFv with a stop codon only in CDRH3. This resulted in $60 \%$ of clones having a functional scFv and it was found that functional scFvs selected against various targets paired the scaffold CDRL3 with numerous CDRH3s.

A semi-synthetic human scFv library (ALTHEA Gold) has been produced that selected for highly diverse thermostable scaffolds before introducing a natural $\mathrm{CDRH} 3$ diversity [53]. Firstly, two kappa VL domains and a single VH domain had diversity introduced using trinucleotide phosphoramidites. These mutations coded for amino acids found in natural repertoires at 10 positions within the $\mathrm{VH}$ (within CDRH1 and CDRH3) and at 10 or 12 positions within the two VLs (within all 3 CDRs). Further diversity was then added by cloning 90 neutral CDRH3 containing fragments, resulting in a library of $\sim 1 \times 10^{9}$ diversity. The selection for high-stability scFv-phage clones was then carried out by heating the library for $10 \mathrm{~min}$ at $70{ }^{\circ} \mathrm{C}$ and purifying stable, native scFvs on protein A (that binds the particular $\mathrm{VH}$ used). This thermostable library of scaffolds was then further diversified by the introduction of natural CDRH3 fragments from 200 donors. The resulting library had a diversity of $\sim 10^{10}$. Binders were selected from the library and once converted to IgG they displayed affinities in the very low 
$\mathrm{nM}$ to $\mathrm{pM}$ range. These $\mathrm{IgGs}$ were produced at $50-90 \mathrm{mg} / \mathrm{L}$ in HEK293 cells.

An alternative approach to scFv library construction has been recently described by Zhao et al. that used the modular cloning of different CDR regions [54]. Antibody sequence databases were mined for heavy and light chain CDR2 and CDR3 sequences contained within a particular $\mathrm{scFv}$ framework. The rationale was that such modular domains are known to be functional and the approach would avoid nonfunctional clones present in synthetic/semi-synthetic libraries. Non-functional clones could arise due to incompatibility between CDR mutations and the framework scaffold(s) and/ or incompatibility between amino acid combinations within highly mutated CDRs. Based on $2000 \mathrm{scFv}$ sequences, shuffling of the $4 \mathrm{CDR}$ regions produced a library of $\sim 10^{10}$ diversity. This so-called predefined CDR sequences (PDC) library was estimated to produce 20 -fold more unique functional scFvs per target compared to libraries produced with degenerate oligonucleotide methods.

As with Fabs, in silico programmes that can predict antibody solubility can also be applied to phage-scFv panning outputs. The aim being to select high affinity binders that also have high solubility without the need for extensive in vitro testing. Sormanni et al. compared the CamSol programme to in vitro solubility tests using nine IgGs derived from scFvs isolated by phage display [55]. Hotspots linked to aggregation were identified within the scFv domain and solubility could be accurately predicted. Such in silico stability prediction tools have now been validated with Fabs and $\mathrm{scFv}$ domains to improve lead antibody identification.

As with Fabs, the reformatting of scFvs into IgGs is important for various applications including the development of therapeutic antibodies. Standard methods involve the sequential cloning of $\mathrm{VL}$ and $\mathrm{VH}$ genes into appropriate IgG expression cassette vector(s), analogous to that for Fabs (Fig. 2a). Alternative methods that allow the batch cloning of scFv sub-libraries after panning selection would be far less labour intensive than cloning individual clones. Such methods would also allow the screening of IgGs for function and therefore facilitate the selection of antibodies with the best properties for the end application. This latter trait has been termed 'screening in product format' (SiPF) by Xiao et al. [56]. As with Fab cloning, the challenge is maintaining the VL-VH pairing during the batch reformatting. Liu and co-workers retained VL-VH combinations when reformatting an scFv sub-library into an IgG format by using overlap extension emulsion PCR [57]. The method produced $1 \times 10^{4}$ IgGs from a panning sub-library and the diversity and relative abundance of clones correlated between the original $\mathrm{scFv}$ library and the $\mathrm{IgG}$ resultant library. Batonick et al. [58] developed a system to reformat $\mathrm{scFv}$ into $\mathrm{IgG}$ that takes advantage of both bacterial integrases and also intron splicing in mammalian cells. Their system, termed pMINERVA, uses a phagemid 'donor' that contains mammalian and bacterial promoters and an $\mathrm{scFv}$ with a linker between the $\mathrm{VH}$ and VL genes that is also the substrate for phiC31 integrase. The construct also contains splice sites either side of the $g I I I$ gene. The gIII gene has an ochre stop at its 3 ' end followed by a splice site and the CL domain (Fig. 3a). The vector containing the $\mathrm{scFv}$ of interest is transduced into an E. coli strain that expresses the integrase and contains an 'acceptor' plasmid. This plasmid contains the $\mathrm{CH}$ domain as well as regulatory elements for mammalian expression (of the light chain). The plasmids undergo specific recombination resulting in an $\mathrm{IgG}$ expression vector where, in mammalian cells, the gIII region is removed by intron splicing resulting in expression of light chain and heavy chain (Fig. 3a). Efficacy was demonstrated for a single $\mathrm{scFv}$ and the method may allow batch reformatting of scFvs of the original library produced in the 'donor' phagemid. An alternative system also allowing batch reformatting uses inverse PCR to amplify $\mathrm{VH}$ and VL within a whole phagemid, effectively producing linear phagemid and removing the linker sequence [59]. This also introduces complementary overhangs. The latter are also used in the separate amplification of a donor fragment containing a hinge- $\mathrm{CH}$ region, translation stop and polyA sites and the control elements for light chain expression (promoter and leader sequence). InFusion [60] technology is then used to fuse this donor fragment into the phagemid. This $\operatorname{IgG}$ cassette is then PCR amplified and cloned into a mammalian expression vector containing the promoter and signal sequence for the heavy chain, the CL domain (either kappa or lambda) and a polyA site (Fig. 3b). When using emulsion PCR to limit recombination between clones, the accuracy of this batch reformatting was $90 \%$ in terms of VH-VL pairing. The study suggested that reformatting retained the relative abundance of clones in an $\mathrm{scFv}$ pool and when reformatting 25 scFvs, $84 \%$ were successfully obtained as IgGs (the missing clones were present just once in the scFv pool when 129 clones were sequenced). Furthermore, when assessing the expression levels of the IgGs, in $293 \mathrm{~F}$ cells, clones produced 0.4-40 mg/L IgG. When using Expi293F cells, expression levels were between 1 and $>200 \mathrm{mg} / \mathrm{L}$ for the 1500 clones assessed. The system is compatible with any pre-existing $\mathrm{scFv}$ library and results in high fidelity batch reformatting and consistent, high-level $\mathrm{IgG}$ production.

An alternative to converting scFvs into IgGs is to produce $\mathrm{scFv}-\mathrm{Fc}$ fusions by cloning the $\mathrm{scFv}$ into a mammalian expression vector containing the $\mathrm{Fc}$ domain in a single step. This format has been shown to produce $10-20 \mathrm{mg} / \mathrm{L}$ in $239 \mathrm{~T}$ cells, which can be optimised to up to $600 \mathrm{mg} / \mathrm{L}$ [61]. Similarly, Xiao et al. [56] developed a vector that allows both bacterial and mammalian expression of $\mathrm{scFv}-\mathrm{Fc}$ fusions. The system, pSplice, is based on a vector that contains mammalian expression control elements followed by an intron coding for a bacterial promoter and signal peptide and then 


\section{A Conversion of scFv into IgG utilising an integrase system (pMINERVA)}

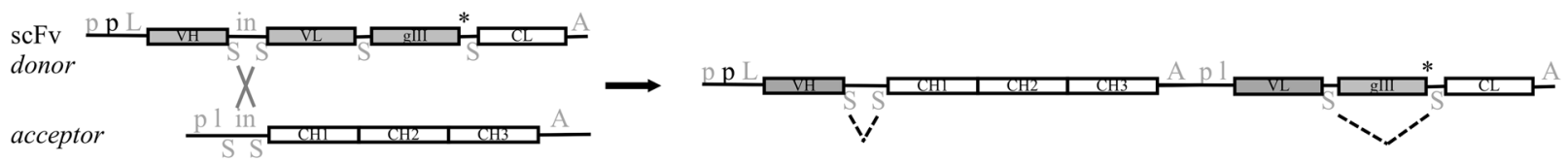

\section{B Conversion of scFv into IgG utilizing inverse PCR and InFusion cloning}
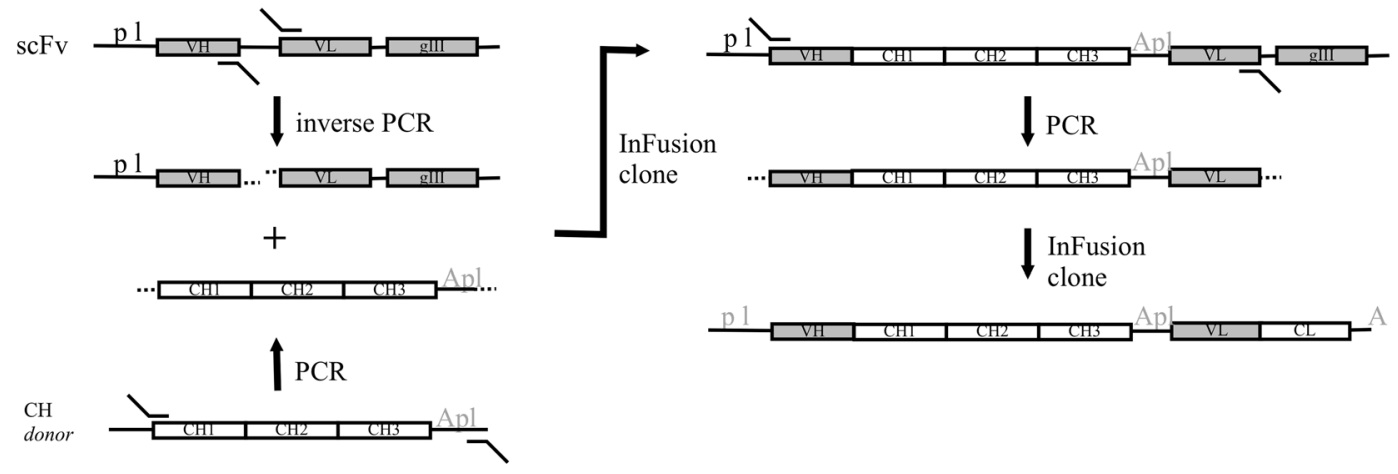

\section{Conversion of scFv into scFv-Fc format (pSplice)}

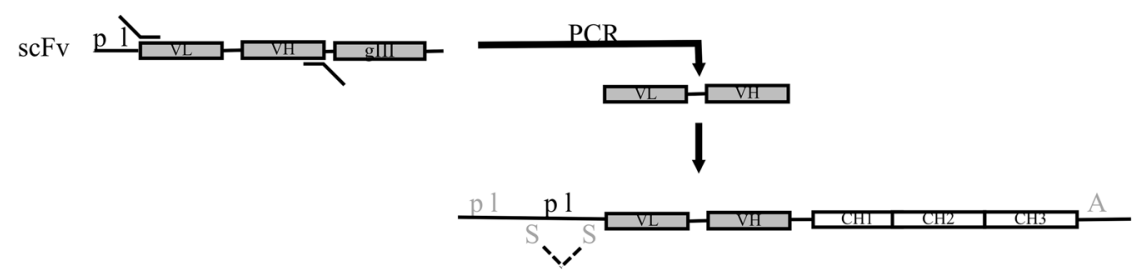

Fig. 3 A summary of key elements within different strategies to produce full-length $\mathrm{IgG}$ or $\mathrm{Fc}$-fusion constructs from scFv-phage display vectors. A conventional 2-step cloning strategy for scFvs is analogous to that for Fabs shown in Fig. 2a. Alternatively, the pMINERVA system [58] utilises both bacterial integrases and also intron splicing in mammalian cells (a). A phagemid 'donor' vector contains mammalian (grey font) and bacterial (black font) promoters and a leader sequence compatible with both cell types (symbols are the same as in Fig. 2), in addition the scFv has a linker that is also the substrate for phiC31 integrase (in). The construct also contains splice sites either side of the integrase substrate region and either side of gIII. The gIII has an ochre stop at its 5' end followed by the CL domain. The construct can be transferred to an E. coli strain that expresses the integrase and where a second acceptor plasmid is present that contains the $\mathrm{CH}$ domain $(\mathrm{CH} 1-\mathrm{CH} 2-\mathrm{CH} 3)$ and regulatory elements (p and 1$)$ for mammalian expression of the light chain. Integrase mediated recombination results in an IgG expression vector where, upon transfer to mammalian cells, intron splicing (dashed lines) results in the removal of the gIII region and expression of light chain and heavy chain. Alternatively, InFusion technology, allowing the cloning of overlapping $15 \mathrm{bp}$ sequences, has been used in a multi-step cloning strategy to produce IgG from scFv [59] (b). The phagemid was ampli-

the scFv-Fc gene. In mammalian cells, the intron is spliced out to produce a functional operon for scFv-Fc (Fig. 3c). This vector system is designed to allow the rapid screening of scFv-Fc using bacterial expression before the transfer of selected clones to mammalian cells. Both systems have the fied by inverse PCR to produce a linear version of the whole vector. This step removed the $\mathrm{scFv}$ linker and added an overlapping sequence (indicated by ...). This same overlapping sequence was added in a separate PCR reaction to a DNA fragment containing $\mathrm{CH}$ domains and mammalian promoter and leader sequences (amplified from a 'donor' vector). InFusion cloning produced the heavy chain and VL region, the latter with mammalian regulatory elements, that are then amplified by PCR and subsequently cloned using InFusion into a mammalian expression vector containing the regulatory elements for the heavy chain as well as the $\mathrm{CL}$ domain. $\mathrm{ScFv}$ from phagemid can potentially be batch cloned into a vector (pSplice) that can express $\mathrm{scFv}-\mathrm{Fc}$ in both bacterial and mammalian cells [56] (c). The scFv could be amplified by PCR and cloned into the pSplice vector that contains a mammalian promoter and leader sequence in addition to $E$. coli promoter and leader sequences, all upstream of the scFv-Fc coding region. The mammalian leader sequence is incomplete with the $3^{\prime}$ region contained after the prokaryotic $\mathrm{p} 1$ sequences that are flanked by splice domains. The scFv-Fc is expressed from the cassette in $E$. coli and in mammalian cells the intron containing the bacterial regulation elements is excised (dashed lines) and the mammalian leader sequence spliced together allowing expression of the scFv-Fc

potential to batch clone $\mathrm{scFv}$ pools after panning to allow the screening of bivalent antibodies.

Another recent advance in $\mathrm{scFv}$-phage display technology is the production of functional, renewable polyclonal $\mathrm{scFv}$ reagents. Polyclonal antibodies produced in vivo are not 
renewable and can often contain as little as $0.5-5 \%$ targetspecific antibodies [62]. The strategy to combine the use of phage and yeast display to screen for binders was described by Ferrara et al. [63]. Two rounds of phage selection against a target were followed by PCR amplification of the scFv sublibrary (representing $\sim 10^{5}-10^{6}$ clones) and batch cloning into a yeast surface display vector. Two rounds of fluorescence activated cell sorting resulted in $\sim 63 \%$ of scFv clones binding the target and all scFvs had low background binding. This polyclonal $\mathrm{scFv}$ reagent was highly specific and could be regenerated after dilution of over a 100 million-fold without loss of function or relative abundance of the clones. The affinities of the reagents were $\sim 50-500 \mathrm{nM}$ which reflected the concentration of antigen that was used in the panning. Such a strategy may have advantages over generating monoclonal ligands when targeting complex antigens presenting multiple epitopes.

\section{Human Single Domain Antibodies}

Whilst far less utilised than scFv or Fab phage display libraries, several single domain human antibody libraries derived from either $\mathrm{VH}$ or $\mathrm{VL}$ regions have been described and characterised $[64,65]$. These are relatively easy to produce as synthetic or semi-synthetic libraries. However, the disadvantages of these antibody formats are the unreliable isolation of target-specific clones by phage display, relatively low stability, low solubility and often relatively poor affinities [64, 65]. Henry et al. [66] attempted to address these limitations by extensively screening human VH and VL scaffolds to isolate those with high stability, solubility, yield and suitability for carrying CDR mutations. They then selected three of the most suitable scaffolds and carried out targeted trinucleotide mutagenesis of CDRs producing libraries of $\sim 10^{10}$ diversity. High affinity ligands (low $\mathrm{nM}$ ) were isolated but the general limitations of human single domain antibodies were not resolved. These issues may be due to human $\mathrm{VH}$ and VL domains usually being paired in nature resulting in the burying of hydrophobic surfaces that are surface exposed in the equivalent single domain structures.

\section{Camelid $\mathrm{V}_{\mathrm{H}} \mathrm{H}$ Nanobodies}

$\mathrm{V}_{\mathrm{H}} \mathrm{Hs}$ are derived from heavy chain antibodies (HCAbs) as first described in 1993 [67] and consist of the equivalent of a conventional IgG VH domain (Fig. 1). HCAbs are naturally found in camels, alpacas and llamas where they make up a significant proportion of the $\mathrm{IgG}$ population. For example, in alpacas $\mathrm{IgGs}$ occur in a ratio of approximately 5:3:2 for IgG1 (conventional IgG structure): $\operatorname{IgG} 2\left(\mathrm{~V}_{\mathrm{H}} \mathrm{H}\right.$ with a short hinge length): $\operatorname{IgG} 3\left(\mathrm{~V}_{\mathrm{H}} \mathrm{H}\right.$ with a long hinge length), and so HCAbs can make up approximately $50 \%$ of circulating IgG [68].

Similarities between $\mathrm{V}_{\mathrm{H}} \mathrm{H}$ and the $\mathrm{VH}$ domain of a typical $\mathrm{IgG}$ are the presence of a disulphide bond between framework regions (FRs) that stabilises the structure, as well as it being composed of 3 CDR regions held by scaffold FRs with beta-sheet structure. Differences between the VH domain and $\mathrm{V}_{\mathrm{H}} \mathrm{H}$ include the latter often having an addition disulphide bond between CDR1 and CDR3 that reduces the flexibility of the paratope, the CDRs 1 and 3 are generally longer in $\mathrm{V}_{\mathrm{H}} \mathrm{H}$ and its FR2 region is more hydrophilic. This latter property prevents the FR2 region interacting with a light chain and also results in higher solubility compared to the $\mathrm{VH}$ domain [69-71]. $\mathrm{V}_{\mathrm{H}} \mathrm{Hs}$ usually have relatively high stability and solubility and can very effectively refold after heat denaturation. Their high stability means they often have a high tolerance to organic solvents [72] and temperature making them very adaptable reagents in assays. $\mathrm{V}_{\mathrm{H}} \mathrm{Hs}$ also have some unusual binding characteristics in that the reduced size of their paratope (made up of 3 rather than 6 CDR regions) with an often extended CDR3 leads to effective binding within 'pockets' such as enzyme active sites. However, $\mathrm{V}_{\mathrm{H}} \mathrm{H}$ binders have been identified to a wide range of antigens including more 'flat' structures [20, 68]. It has been suggested that a relatively small paratope may be a disadvantage when binding haptens, and whilst in vivo camelid antibodies against such antigens tend to be dominated by IgG1, there are numerous examples where phage displayed $\mathrm{V}_{\mathrm{H}} \mathrm{Hs}$ have been isolated to haptens [20], indicating they have a broad range of potential epitopes. When considering $\mathrm{V}_{\mathrm{H}} \mathrm{Hs}$ as in vivo reagents, their small size may allow superior tissue/tumour penetration compared to larger antibody formats, their lack of an $\mathrm{Fc}$ region means they provoke less immune effector responses and they have a relatively rapid distribution and subsequent clearance. These traits indicate that they are good candidates as ligands for producing high contrast images [72]. Indeed, single domain antibodies have already been developed into various molecular imaging tracers [73-77]. $\mathrm{V}_{\mathrm{H}} \mathrm{Hs}$ with potential therapeutic applications have also recently been described [78-80].

The isolation of $\mathrm{V}_{\mathrm{H}} \mathrm{Hs}$ often involves the immunisation of camelids and the subsequent production of an immune phage display library. Obvious limitations of this approach are that each library is only valid for a single (or limited number) of antigens, the cost of keeping the animals is high and toxic antigens cannot be used. However, there are now in vitro alternatives to this approach. One strategy that has been recently demonstrated is to stimulate camelid B cells in vitro with antigen in the presence of IL2 and IL4 and then clone a small $\mathrm{V}_{\mathrm{H}} \mathrm{H}$ display library of $\sim 10^{6}$ repertoire [81]. Alternatively, single-pot $\mathrm{V}_{\mathrm{H}} \mathrm{H}$ phage display libraries have been produced and range in diversity from $\sim 10^{7}$ to $\sim 10^{9}[18$, $69,82-85]$. These can be produced from natural diversity 
or by engineering diversity into the CDR regions of a scaffold $\mathrm{V}_{\mathrm{H}} \mathrm{H}$. For example, Sabir and co-workers amplified and cloned the natural diversity of $\mathrm{V}_{\mathrm{H}} \mathrm{Hs}$ for both $\mathrm{IgG} 2$ and $\mathrm{IgG} 3$ producing a library with $10^{7}$ diversity [69]. For synthetic libraries, Yan et al. [18] used the $\mathrm{cAbBCII} 10 \mathrm{~V}_{\mathrm{H}} \mathrm{H}$ template as an effective scaffold for grafting in CDR diversity, this scaffold has high stability and expression levels and lacks the CDR1-CDR3 disulphide bond [86]. They introduced a 16-amino acid random insert into the CDR3, using the NNK codon, to produce a $10^{9}$ library. Cloning used an overlapping PCR method to amplify the $\mathrm{V}_{\mathrm{H}} \mathrm{H}$ gene with the overlap in the FR3 domain. Interestingly, $\mathrm{V}_{\mathrm{H}} \mathrm{Hs}$ isolated from this library against distinct targets had very different expression levels in bacteria indicating the significant contribution of the CDR3 region to antibody yields.

The expression levels of $\mathrm{V}_{\mathrm{H}} \mathrm{Hs}$ is relatively high in both bacterial and eukaryotic expression systems and this is often accompanied by high thermal stability. For example, bacterial expression often produces $>5 \mathrm{mg} / \mathrm{L}$ of $\mathrm{V}_{\mathrm{H}} \mathrm{H}[18,71$, 86]. Studies have looked at further improving thermal stability $[87,88]$ by the introduction of an extra disulphide bond between FR2 and FR3. This approach usually increased thermal stability but often resulted in lower expression levels and in one case also reduced refolding after heat denaturation [71]. An additional strategy was to then introduce negatively charged amino acid substitutions into FRs to lower the isoelectric point of the $\mathrm{V}_{\mathrm{H}} \mathrm{H}$. This was shown to improve expression and refolding properties for some antibodies [71], however, it did not increase yields for all $\mathrm{V}_{\mathrm{H}} \mathrm{Hs}$ with the extra disulphide bond. Overall, this strategy presents an additional or alternative approach for the stabilisation of $\mathrm{V}_{\mathrm{H}} \mathrm{Hs}$.

In summary, $\mathrm{V}_{\mathrm{H}} \mathrm{Hs}$ have greater stability than other antibody formats and are expressed at relatively high levels in bacteria. Their smaller size and smaller paratope does not seem to constrain the binding properties of $\mathrm{V}_{\mathrm{H}} \mathrm{Hs}$ isolated in vitro. $\mathrm{V}_{\mathrm{H}} \mathrm{Hs}$ may also offer advantages when targeting 'buried' epitopes such as the active sites of enzymes. Compared to other antibody formats, $\mathrm{V}_{\mathrm{H}} \mathrm{Hs}$ may also offer improved tumour penetration for in vivo applications. Improving $\mathrm{V}_{\mathrm{H}} \mathrm{H}$ in vivo properties such as effector function and increased serum half-life may be achieved by fusion to an $\mathrm{Fc}$ domain. This has been achieved for individual $\mathrm{V}_{\mathrm{H}} \mathrm{Hs}$ [89] and should be feasible for batch reformatting of $\mathrm{V}_{\mathrm{H}} \mathrm{Hs}$ from phage display experiments in analogous procedures to those for $\mathrm{scFv}-\mathrm{Fc}$ and scFab-Fc formats.

\section{Shark $\mathbf{V}_{\text {NAR }}$ Nanobodies}

There are relatively few examples of $\mathrm{V}_{\mathrm{NAR}}$ phage display libraries compared to $\mathrm{scFv}, \mathrm{Fab}$ and $\mathrm{V}_{\mathrm{H}} \mathrm{H}$ formats. The $\mathrm{V}_{\mathrm{NAR}}$ structure is analogous to $\mathrm{V}_{\mathrm{H}} \mathrm{H}$ in that it has a relatively long
CDR3 region of up to 40 amino acids, averaging $~ 18$ residues $[19,90]$ and this region represent most of the diversity. They also have disulphide bonds that stabilise their structure (including a canonical bond between FR1 and FR3), and are relatively small at $\sim 12 \mathrm{kDa}$. Similar to $\mathrm{V}_{\mathrm{H}} \mathrm{Hs}, \mathrm{V}_{\mathrm{NAR}} \mathrm{S}$ are highly stable. However, $\mathrm{V}_{\mathrm{NAR}} \mathrm{S}$ do not have a CDR2 region, instead they have 2 mutation-prone regions between CDR1 and CDR3 termed HV2 and HV4 $[19,91]$. The $\mathrm{V}_{\mathrm{NAR}} \mathrm{S}$ are classified as Type 1 to Type 4 depending on the number and location of non-canonical disulphide bonds [18, 91]. Type 1 contains 2 cysteine residues in CDR 3 that form bonds with residues in FR1 and FR4, type 2 have a bond between CDR3 and CDR 1 , type 3 are similar to type 2 but with a conserved tryptophan adjacent to the bond location in CDR1 and type 4 have none of the non-canonical bonds that are seen in the other 3 types. Feng et al. also describe further types of $\mathrm{V}_{\mathrm{NAR}} \mathrm{S}$ that are yet to be classified [19]. Type 1, 2 and unclassified $\mathrm{V}_{\mathrm{NAR}} \mathrm{S}$ with specific binding properties have been isolated from phage display experiments $[19,90,92-94] . \mathrm{V}_{\mathrm{NAR}} \mathrm{S}$ are from a single gene family and so are very easily cloned, just 3 primers in 2 PCR reactions have been used to clone $V_{\text {NAR }}$ diversity [90]. Both immune and single-pot phage libraries have been produced. Immune libraries of $\sim 10^{6}$ to $10^{7}$ diversity have been reported $[90,94,95]$, one of which yielded an antibody with low nM affinity [90]. Up until very recently, single-pot libraries were produced from a range of shark species but with relatively low diversities of $\sim 10^{7}[92,93$, 95, 96]. These libraries were either synthetic [92, 97] based on up to 26 scaffold sequences and randomised CDR3, a mixture of synthetic CDR3 diversity and natural diversity [93] or had completely natural diversity [96]. A naïve library with high diversity has recently been produced by Feng et al. [19]. They used a method termed PCR extension assembly and self-ligation (EASeL) to produce a library with diversity of $\sim 1 \times 10^{10}$. The method amplified the $\mathrm{V}_{\mathrm{NAR}}$ gene region and a phagemid vector separately, both with a complementary overhang. Both products were then amplified together in a subsequent extension PCR, followed by self-ligation. The library was used to isolate binders to diverse targets and one binder had an affinity of $10 \mathrm{nM}$. Across all studies, the $\mathrm{V}_{\mathrm{NAR}} \mathrm{S}$ could be produced in $E$. coli but with varying levels of expression, between $\sim 0.2$ and $15 \mathrm{mg} / \mathrm{L}[19,93]$. Zadeh et al. has also produced a synthetic $\mathrm{V}_{\mathrm{NAR}}$ library based on the anti-lysozyme HEL-5A7 $\mathrm{V}_{\mathrm{NAR}}$ clone, introducing diversity into a 12 to 23 amino acid CDR3 [98].

As with $\mathrm{V}_{\mathrm{H}} \mathrm{Hs}$, batch reformatting of $\mathrm{V}_{\mathrm{NAR}} \mathrm{s}$ into IgGlike structures to improve in vivo properties has not been reported. However, individual $\mathrm{V}_{\mathrm{NAR}} \mathrm{s}$ have been converted into $\mathrm{V}_{\mathrm{NAR}}-\mathrm{Fc}$ fusions [99]. Batch reformatting of this type of antibody should therefore be feasible using analogous procedures to those for $\mathrm{scFv}-\mathrm{Fc}$ and $\mathrm{scFab}-\mathrm{Fc}$ formats. 


\section{Conclusions and Future Perspectives}

This review has considered the phage display of Fabs, scFvs and nanobodies. With potential application to all recombinant antibody library types are the recent improvement in library design and display efficiency. The diversity within the CDR regions can now be designed with considerable accuracy by using trimer phosphoramidine codons to mimic natural amino acid usage [52]. Furthermore, improvements have been made in reducing cloning errors due to the presence of linker repeat regions [49]. Both advances will facilitate the optimal cloning of diversity into libraries in the future. The co-expression of chaperones and isomerases $[34,36]$ as well as the use of the co-translation secretion pathway with optimised signal sequences [25] can significantly improve antibody phage display efficiency, thereby improving the efficiency of isolating binders. These same strategies also improve soluble antibody expression levels. Furthermore, the identification and use of highly stable Fabs and scFvs as scaffold for the introduction of synthetic diversity have improved expression and stability of the resulting antibody fragments $[31,32,50,66]$. The combined use of these strategies to yield higher expression levels and increased stability has the potential to produce more efficient phage display of antibodies and therefore improve panning efficacy. They should also produce more useful reagents.

Methods suitable for the batch reformatting of both Fabs and scFvs into IgGs for high-level expression in mammalian cell culture are now also described [26, 27, 58, 59]. These will facilitate the efficient cloning of sub-libraries of antibody fragments from panning experiments to allow them to be screened as IgGs. This has previously been a bottleneck in developing therapeutics from phage display libraries, as the monovalent recombinant antibody fragments often have very different properties to their concomitant divalent IgGs.

Nanobodies from both camelids and sharks are readily amenable to the production of simple, high diversity phage display libraries $[18,19]$. They provide small antibodies with very high stability, therefore potentially offering unique properties for diagnostic or even therapeutic applications. In addition, the production of renewable polyclonal $\mathrm{scFv}$ from phage display experiments has now been demonstrated and may also provide a new type of diagnostic reagent [63].

Overall, improved methods for the accurate cloning of libraries, more efficient display of antibodies on phage, improved expression levels for soluble antibodies and the ability to screen in multiple antibody formats has the potential to significantly improve the application of phage display to generate an ever-wider range of diagnostic and therapeutic antibodies.

Acknowledgements This work was supported by the Biotechnology and Biological Sciences Research Council [Grant Number BB/ J014508/1].
Open Access This article is distributed under the terms of the Creative Commons Attribution 4.0 International License (http://creativeco mmons.org/licenses/by/4.0/), which permits unrestricted use, distribution, and reproduction in any medium, provided you give appropriate credit to the original author(s) and the source, provide a link to the Creative Commons license, and indicate if changes were made.

\section{References}

1. Smith, G. P., \& Petrenko, V. A. (1997). Phage display. Chemical Reviews, 97, 391-410.

2. Carmen, S., \& Lutz, J. (2002). Concepts in antibody phage display. Briefings in Functional Genomics Proteomics, 1, 189-203.

3. Paschke, M. (2006). Phage display systems and their applications. Applied Microbiology and Biotechnology, 70, 2-11.

4. Zhang, H., Torkmani, A., Jones, T. M., Ruiz, D. I., Pons, J., \& Lerner, R. A. (2011). Phenotype-information-phenotype cycle for deconvolution of combinatorial antibody libraries selected against complex systems. Proceedings of the National Academy of Sciences USA, 108, 13456-13461.

5. D’Angelo, S., Kumar, S., Naranjo, L., Ferrara, F., Kiss, C., \& Bradbury, A. R. M. (2014). From deep sequencing to actual clones. Protein Engineering, Design \& Selection, 27, 301-307.

6. Miyazaki, N., Kiyose, N., Akazawa, Y., Takashima, M., Hagihara, Y., Inoue, N., et al. (2015). Isolation and characterisation of antigen-specific alpaca (Lama pacos) $\mathrm{V}_{\mathrm{H}} \mathrm{H}$ antibodies by biopanning followed by high-throughput sequencing. Journal of Biochemistry, 158, 205-215.

7. Li, Y., Cockburn, W., Kilpatrick, J. B., \& Whitelam, G. C. (2000). High affinity scFvs from a single rabbit immunized with multiple haptens. Biochemical and Biophysical Research Communications, 16, 398-404.

8. Gough, K. C., Maddison, B. C., Shikotra, A., Moiseeva, A. P., Yang, W., Jarvis, S., et al. (2015). Evidence for a novel Kit adhesion domain mediating human mast cell adhesion to structural airway cells. Respiratory Research, 16, 86.

9. Kühne, S. A., La Hawes, W. S., Ragion, R. M., Woodward, M. J., Whitelam, G. C., \& Gough, K. C. (2004). Isolation of recombinant antibodies against espA and intimin of of Escherichia coli O157:H7. Journal of Clinical Microbiology, 42, 2966-2976.

10. Omar, N., \& Lim, T. S. (2018). Construction of naïve and immune human Fab phage-display libraries. In M. Hust \& T. S. Lim (Eds.), Phage display, vol 1701: Methods in molecular biology (pp. 25-44). New York: Humana Press.

11. Rahumatullah, A., Ahmad, A., Rahmah, N., \& Lim, T. S. (2015). Delineation of BmSXP antibody V-gene usage from a lymphatic filariasis based immune scFv antibody library. Molecular Immunology, 67, 512-523.

12. Vaughan, T. J., Williams, A. J., Pritchard, K., Osbourn, J. K., Pope, A. R., Earnshaw, J. C., et al. (1996). Human antibodies with sub-nanomolar affinities isolated from a large non-immunized phage display library. Nature Biotechnology, 14, 309-314.

13. Goletz, S., Christensen, P. A., Kristensen, P., Blohm, D., Tomlinson, I., Winter, G., et al. (2002). Selection of large diversities of antiidiotypic antibody fragments by phage display. Journal of Molecular Biology, 315, 1087-1097.

14. Knappik, A., Ge, L., Honegger, A., Pack, P., Fischer, M., Wellnhofer, G., et al. (2000). Fully synthetic human combinatorial antibody libraries (HuCAL) based on modular consensus frameworks and CDRs randomized with trinucleotides. Journal of Molecular Biology, 296, 57-86.

15. Rauchenberger, R., Borges, E., Thomassen-Wolf, E., Rom, E., Adar, R., Yaniv, Y., et al. (2003). Human combinatorial Fab library yielding specific and functional antibodies against the 
human fibroblast growth factor receptor 3. Journal of Biological Chemistry, 278, 38194-38205.

16. Rothe, C., Urlinger, S., Löhning, C., Prassler, J., Stark, Y., Jäger, U., et al. (2008). The human combinatorial antibody library HuCAL GOLD combines diversification of all six CDRs according to the natural immune system with a novel display method for efficient selection of high-affinity antibodies. Journal of Molecular Biology, 376, 1182-1200.

17. Kang, A. S., Barbas, C. F., Janda, K. D., Benkovic, S. J., \& Lerner, R. A. (1991). Linkage of recognition and replication functions by assembling combinatorial antibody Fab libraries along phage surfaces. Proceedings of the National Academy of Sciences USA, 88, 4363-4366.

18. Yan, J., Li, G., Hu, Y., Ou, W., \& Wan, Y. (2014). Construction of a synthetic phage-displayed Nanobody library with CDR3 regions randomized by trinucleotide cassettes for diagnostic applications. Journal of Translational Medicine, 12, 343.

19. Feng, M., Bian, H., Wu, X., Fu, T., Fu, Y., Hong, J., et al. (2019). Construction and next generation sequencing analysis of a large phage-displayed $\mathrm{V}_{\mathrm{NAR}}$ single-domain antibody library from six naïve nurse sharks. Antibody Therapeutics, 2, 1-11.

20. Gonzalez-Sapienza, G., Rossotti, M. A., \& Tabares-da, Rosa S. (2017). Single-domain antibodies as versatile affinity reagents for analytical and diagnostic applications. Frontiers in Immunology, 8, 977.

21. Jostock, T., Vanhove, M., Brepoels, E. Van, Gool, R., Daukandt, M., Wehnert, A. Van, et al. (2004). Rapid generation of functional human $\mathrm{IgG}$ antibodies derived from Fab-on-phage display libraries. Journal of Immunological Methods, 289, 65-80.

22. Frenzel, A., Kügler, J., Helmsing, S., Meier, D., Schirrmann, T., Hust, M., et al. (2017). Designing human antibodies by phage display. Transfusion Medicine and Hemotherapy, 44, 312-318.

23. Frenzel, A., Schirrmann, T., \& Hust, M. (2016). Phage displayderived human antibodies in clinical development and therapy. $m A b s, 8,1177-1194$

24. Kaplon, H., \& Reichert, M. (2019). Antibodies to watch in 2019. $m A b s, 11,219-238$.

25. Koerber, J. T., Hornsby, M. J., \& Wells, J. A. (2015). An improved single-chain Fab platform for efficient display and recombinant expression. Journal of Molecular Biology, 427, 576-586.

26. Tesar, D., \& Hötzel, I. (2013). A dual host vector for Fab phage display and expression of native IgG in mammalian cells. Protein Engineering, Design \& Selection, 26, 655-662.

27. Nelson, R. S., \& Valadon, P. (2017). A universal phage display system for the seamless construction of Fab libraries. Journal of Immunological Methods, 450, 41-49.

28. Weber, J., Peng, H., \& Rader, C. (2017). From rabbit antibody repertoires to rabbit monoclonal antibodies. Experimental \& Molecular Medicine, 49, e305.

29. Peng, H., Nerreter, T., Chang, J., Qi, J., Li, X., Karunadharma, P., et al. (2017). Mining naïve rabbit antibody repertoires by phage display for monoclonal antibodies of therapeutic utility. Journal of Molecular Biology, 429, 2954-2973.

30. Tiller, T., Schuster, I., Deppe, D., Siegers, K., Strohner, R., Herrmann, T., et al. (2013). A fully synthetic human Fab antibody library based on fixed VH/VL framework pairings with favorable biophysical properties. $m A b s, 5,445-470$.

31. Lee, C. V., Sidhu, S. S., \& Fuh, G. (2004). Bivalent antibody phage display mimics natural immunoglobulin. Journal of Immunological Methods, 284, 119-132.

32. Entzminger, K. C., Johnson, J. L., Hyun, J., Lieberman, R. L., \& Maynard, J. A. (2015). Increased Fab thermoresistance via VH-targeted directed evolution. Protein Engineering, Design \& Selection, 10, 365-377.
33. Wolf Perez, A.-M., Sormanni, P., Andersen, J. S., Sakhnini, L. I., Rodriguez-Leon, I., Bjelke, J. R., et al. (2019). In vitro and in silico assessment of the developability of a designed monoclonal antibody library. $m A b s, 11,388-400$.

34. Loh, Q., Leong, S. W., Tye, G. J., Choong, Y. S., \& Lim, T. S. (2015). Improved Fab presentation on phage surface with the use of molecular chaperone coplasmid system. Analytical Biochemistry, 477, 56-61.

35. Huovinen, T., Syrjänpää, M., Sanmark, H., Seppä, T., Akter, S., Khan, L. M., et al. (2014). The selection performance of an antibody library displayed on filamentous phage coat proteins $\mathrm{p} 9, \mathrm{p} 3$ and truncated p3. BMC Research Notes, 7, 661.

36. Levy, R., Ahluwalia, K., Bohmann, D. J., Giang, H. M., Schwimmer, L. J., Issafras, H., et al. (2013). Enhancement of antibody fragment secretion into the Escherichia coli periplasm by co-expression with the peptidyl prolyl isomerase, FkpA, in the cytoplasm. Journal of Immunological Methods, 394, 10-21.

37. Zuberbühler, K., Palumbo, A., Bacci, C., Giovannoni, L., Sommavilla, R., Kaspar, M., et al. (2008). A general method for the selection of high-level scFv and IgG antibody expression by stably transfected mammalian cells. Protein Engineering, Design \& Selection, 22, 169-174.

38. Skerra, A., Pfitzinger, I., \& Plückthun, A. (1993). The functional expression of antibody $\mathrm{Fv}$ fragments in Escherichia coli: Improved vectors and a generally applicable purification technique. Bio/Technology, 9, 273-278.

39. Bird, R. E., \& Walker, B. W. (1991). Single chain variable regions. Trends in Biotechnology, 9, 132-137.

40. Weisser, N. E., \& Hall, J. C. (2009). Applications of single-chain variable fragment antibodies in therapeutics and diagnostics. Biotechnology Advances, 27, 502-520.

41. Schwimmer, L. J., Huang, B., Giang, H., Cotter, R. L., ChemlaVogel, D. S., Dy, F. V., et al. (2013). Discovery of diverse and functional antibodies from large human repertoire antibody libraries. Journal of Immunological Methods, 391, 60-71.

42. Putelli, A., Kiefer, J. D., Zadory, M., Matasci, M., \& Neri, D. (2014). A fibrin-specific monoclonal antibody from a designed phage display library inhibits clot formation and localizes to tumors in vivo. Journal of Molecular Biology, 426, 3606-3618.

43. Kügler, J., Wilke, S., Meier, D., Tomszak, F., Frenzel, A., Schirrmann, T., et al. (2015). Generation and analysis of the improved human HAL9/10 antibody phage display libraries. BMC Biotechnology, 15, 10.

44. Clark, M. (2000). Antibody humanization: a case of the 'Emperor's new clothes'? Immunology Today, 21, 397-402.

45. Verhaar, M. J., Chester, K. A., Keep, P. A., Robson, L., Pedley, R. B., Boden, J. A., et al. (1995). A single chain Fv derived from a filamentous phage library has distinct tumor targeting advantages over one derived from a hybridoma. International Journal of Cancer, 61, 497-501.

46. Mao, S., Gao, C., Lo, C. H., Wirsching, P., Wong, C. H., \& Janda, K. D. (1999). Phage-display library selection of high-affinity human single-chain antibodies to tumor-associated carbohydrate antigens sialyl Lewis ${ }^{\mathrm{x}}$ and Lewis ${ }^{\mathrm{x}}$. Proceedings of the National Academy of Sciences USA, 96, 6953-6958.

47. Dorfmueller, S., Tan, H. C., Ngoh, Z. X., Toh, K. Y., Peh, G., Ang, H. P., et al. (2016). Isolation of a recombinant antibody specific for a surface marker of the corneal endothelium by phage display. Scientific Reports, 6, 21661.

48. Ossysek, K., Uchański, T., Kulesza, M., Bzowska, M., Klaus, T., Woś, K., et al. (2015). A new expression vector facilitating production and functional analysis of $\mathrm{scFv}$ antibody fragments selected from Tomlinson $\mathrm{I}+\mathrm{J}$ phagemid libraries. Immunology Letters, 167, 95-102. 
49. Nishi, M., Jian, N., Yamamoto, K., Seto, H., Nishida, Y., Tonoyama, Y., et al. (2014). Ligation-based assembly for constructing mouse synthetic scFv libraries by chain shuffling with in vivoamplified VH and VL fragments. Journal of Immunological Methods, 412, 53-69.

50. Weber, M., Bujak, E., Putelli, A., Villa, A., Matasci, M., Gualandi, L., et al. (2014). A highly functional synthetic phage display library containing over 40 billion human antibody clones. PLOS ONE, 9, e100000.

51. Hu, D., Hu, S., Wan, W., Xu, M., Du, R., Zhao, W., et al. (2015). Effective optimization of antibody affinity by phage display integrated with high-throughput DNA synthesis and sequencing technologies. PLOS ONE, 10, e0129125.

52. Säll, A., Walle, M., Wingren, C., Müller, S., Nyman, T., Vala, A., et al. (2016). Generation and analyses of human synthetic antibody libraries and their application for protein microarrays. Protein Engineering, Design \& Selection, 29, 427-437.

53. Valadon, P., Pérez-Tapia, S. M., Nelson, R. S., Guzmán-Bringas, O. U., Arrieta-Oliva, H. I., Gómez-Castellano, K. M., et al. (2019). ALTHEA Gold Libraries ${ }^{\mathrm{TM}}$ : Antibody libraries for therapeutic antibody discovery. $m A b s, 11,516-531$.

54. Zhao, Q., Buhr, D., Gunter, C., Frenette, J., Ferguson, M., Sanford, E., et al. (2018). Rational library design by functional CDR resampling. New Biotechnology, 45, 89-97.

55. Sormanni, P., Amery, L., Ekizoglou, S., Vendruscolo, M., \& Popovic, B. (2018). Rapid and accurate in silico solubility screening of a monoclonal antibody library. Scientific Reports, 7, 8200.

56. Xiao, X., Chen, Y., Mugabe, S., Gao, C., Tkaczyk, C., Mazor, Y., et al. (2015). A novel dual expression platform for high throughput functional screening of phage libraries in product like format. PLOS ONE, 10, e0140691.

57. Liu, Y., Gu, M., Wu, Y., Wang, W., Wang, R., Du, M., et al. (2018). High-throughput reformatting of phage-displayed antibody fragments to IgGs by one-step emulsion PCR. Protein Engineering, Design \& Selection, 31, 427-436.

58. Batonick, M., Kiss, M. M., Fuller, E. P., Magadan, C. M., Holland, E. G., Zhao, Q., et al. (2016). pMINERVA: A donoracceptor system for the in vivo recombineering of scFv into $\mathrm{IgG}$ molecules. Journal of Immunological Methods, 431, 22-30.

59. Xiao, X., Douthwaite, J. A., Chen, Y., Kemp, B., Kidd, S., Percival-Alwyn, J., et al. (2017). A high-throughput platform for population reformatting and mammalian expression of phage display libraries to enable functional screening as full-length IgG. $m A b s, 9,996-1006$.

60. Park, J., Throop, A. L., \& LaBaer, J. (2015). Site-specific recombinational cloning using gateway and in-fusion cloning schemes. Current Protocols in Molecular Biology, 110, 3.20.1-3.20.23.

61. Jäger, V., Büssow, K., Wagner, A., Weber, S., Hust, M., Frenzel, A., et al. (2013). High level transient production of recombinant antibodies and antibody fusion proteins in HEK293 cells. BMC Biotechnology, 13, 52.

62. Nilsson, P., Paavilainen, L., Larsson, K., Odling, J., Sundberg, M., Andersson, A. C., et al. (2005). Towards a human proteome atlas: high-throughput generation of monospecific antibodies for tissue profiling. Proteomics, 5, 4327-4337.

63. Ferrara, F., D’Angelo, S., Gaiotto, T., Naranjo, L., Tian, H., Graslund, S., et al. (2015). Recombinant renewable polyclonal antibodies. $m A b s, 7,32-41$.

64. Henry, K. A., Kandalaft, H., Lowden, M. J., van Rossotti, M. A., Faassen, H., Hussack, G., et al. (2017). A disulfide-stabilized human VL single-domain antibody library is a source of soluble and highly thermostable binders. Molecular Immunology, 90, 190-196.

65. Henry, K. A., \& Tanha, J. (2018). Performance evaluation of phage-displayed synthetic human single-domain antibody libraries: A retrospective analysis. Journal of Immunological Methods, 456, 81-86.

66. Henry, K. A., Kim, D. Y., Kandalaft, H., Lowden, M. J., Yang, Q., Schrag, J. D., et al. (2017). Stability-diversity tradeoffs impose fundamental constraints on selection of synthetic human VH/VL single-domain antibodies from in vitro display libraries. Frontiers in Immunology, 8, 1759.

67. Hamers-Casterman, C., Atarhouch, T., Muyldermans, S., Robinson, G., Hamers, C., Songa, E. B., et al. (1993). Naturally occurring antibodies devoid of light chains. Nature, 363, 446-448.

68. Maassa, D. R., Sepulvedac, J., Pernthanerb, A., \& Shoemakerc, C. B. (2007). Alpaca (Lama pacos) as a convenient source of recombinant camelid heavy chain antibodies $\left(\mathrm{V}_{\mathrm{H}} \mathrm{Hs}\right)$. Journal of Immunological Methods, 324, 13-25.

69. Sabir, J. S. M., Atef, A., El-Domyati, F. M., Edris, S., Hajrah, N., Alzohairy, A. M., et al. (2014). Construction of naïve camelids $\mathrm{V}_{\mathrm{H}} \mathrm{H}$ repertoire in phage display-based library. Comptes Rendus Biologies, 337, 244-249.

70. Govaert, J., Pellis, M., Deschacht, N., Vincke, C., Conrath, K., Muyldermans, S., et al. (2012). Dual beneficial effect of interloop disulfide bond for single domain antibody fragments. Journal of Biological Chemistry, 287, 1970-1979.

71. Liu, J. L., Goldman, E. R., Zabetakis, D., Walper, S. A., Turner, K. B., Shriver-Lake, L. C., et al. (2015). Enhanced production of a single domain antibody with an engineered stabilizing extra disulfide bond. Microbial Cell Factories, 14, 158.

72. Dona, V., Urrutia, M., Bayardo, M., Alzogaray, V., Goldbaum, F. A., \& Chirdo, F. G. (2010). Single domain antibodies are specially suited for quantitative determination of gliadins under denaturing conditions. Journal of Agriculture and Food Chemistry, 58, 918-926.

73. De Vos, J., Devoogdt, N., Lahoutte, T., \& Muyldermans, S. (2013). Camelid single-domain antibody-fragment engineering for (pre)clinical in vivo molecular imaging applications: Adjusting the bullet to its target. Expert Opinion on Biological Therapy, $13,1149-1160$.

74. D'huyvetter, M., Xavier, C., Caveliers, V., Lahoutte, T., Muyldermans, S., \& Devoogdt, N. (2014). Radiolabeled nanobodies as theranostic tools in targeted radionuclide therapy of cancer. Expert Opinion on Drug Delivery, 11, 1939-1954.

75. Huang, L., Gainkam, L. O., Caveliers, V., Vanhove, C., Keyaerts, M. De, Baetselier, P., et al. (2008). SPECT imaging with 99mTclabeled EGFR-specific nanobody for in vivo monitoring of EGFR expression. Molecular Imaging \& Biology, 10, 167-175.

76. Schoonooghe, S., Laoui, D. Van, Ginderachter, J. A., Devoogdt, N., Lahoutte, T. De, Baetselier, P., et al. (2012). Novel applications of nanobodies for in vivo bio-imaging of inflamed tissues in inflammatory diseases and cancer. Immunobiology, 217, $1266-1272$.

77. Keyaerts, M., Xavier, C., Heemskerk, J., Devoogdt, N., Everaert, H., Ackaert, C., et al. (2016). Phase I study of 68 Ga-HER2nanobody for PET/CT assessment of HER2 expression in breast carcinoma. Journal of Nuclear Medicine, 57, 27-33.

78. Mejias, M. P., Hiriart, Y., Lauche, C., Fernandez-Brando, R. J., Pardo, R., Bruballa, A., et al. (2016). Development of camelid single chain antibodies against Shiga toxin type 2 (Stx2) with therapeutic potential against hemolytic uremic syndrome (HUS). Scientific Reports, 6, 24913.

79. Malik, A. A., Imtong, C., Sookrung, N., Katzenmeier, G., Chaicumpa, W., \& Angsuthanasombat, C. (2016). Structural characterization of humanized nanobodies with neutralizing activity against the Bordetella pertussis CyaA-hemolysin: Implications for a potential epitope of toxin-protective antigen. Toxins (Basel), $8,99$.

80. Lemaire, M., D'huyvetter, M., Lahoutte, T., Van Valckenborgh, E., Menu, E., De Bruyne, E., et al. (2014). Imaging and 
radioimmunotherapy of multiple myeloma with anti-idiotypic Nanobodies. Leukemia, 28, 444-447.

81. Comor, L., Dolinska, S., Bhide, K., Pulzova, L., Jiménez-Munguía, I., Bencurova, E., et al. (2017). Joining the in vitro immunization of alpaca lymphocytes and phage display: rapid and cost effective pipeline for sdAb synthesis. Microbial Cell Factories, $16,13$.

82. Monegal, A., Ami, D., Martinelli, C., Huang, H., Aliprandi, M., Capasso, P., et al. (2009). Immunological applications of single domain llama recombinant antibodies isolated from a naïve library. Protein Engineering, Design \& Selection, 22, 273-280.

83. Dong, J., Thompson, A. A., Fan, Y., Lou, J., Conrad, F., Ho, M., et al. (2010). A single-domain llama antibody potently inhibits the enzymatic activity of botulinum neurotoxin by binding to the non-catalytic alpha-exosite binding region. Journal of Molecular Biology, 397, 1106-1118.

84. Thanongsaksrikul, J., Srimanote, P., Maneewatch, S., Choowongkomon, K., Tapchaisri, P., Makino, S., et al. (2010). A $\mathrm{V}_{\mathrm{H}} \mathrm{H}$ that neutralizes the zinc metalloproteinase activity of botulinum neurotoxin type A. Journal of Biological Chemistry, 285, 9657-9666.

85. Verheesen, P., de Roussis, A., Haard, H. J., Groot, A. J., den Stam, J. C., Dunnen, J. T., et al. (2006). Reliable and controllable antibody fragment selections from Camelid non-immune libraries for target validation. Biochimica et Biophysica Acta, 1764, 1307-1319.

86. Saerens, D., Pellis, M., Loris, R., Pardon, E., Dumoulin, M., Matagne, A., et al. (2005). Identification of a universal $\mathrm{V}_{\mathrm{H}} \mathrm{H}$ framework to graft non-canonical antigen-binding loops of camel single-domain antibodies. Journal of Molecular Biology, 352, 597-607.

87. Hagihara, Y., Mine, S., \& Uegaki, K. (2007). Stabilization of an immunoglobulin fold domain by an engineered disulfide bond at the buried hydrophobic region. Journal of Biological Chemistry, 282, 36489-36495.

88. Saerens, D., Conrath, K., Govaert, J., \& Muyldermans, S. (2008). Disulfide bond introduction for general stabilization of immunoglobulin heavy-chain variable domains. Journal of Molecular Biology, 377, 478-488.

89. Qasemi, M., Behdani, M., Shokrgozar, M. A., Molla-Kazemiha, V., Mohseni-Kuchesfahani, H., \& Habibi-Anbouhi, M. (2016). Construction and expression of an anti-VEGFR2 nanobody-Fc fusionbody in NSO host cells. Protein Expression and Purification, 123, 19-25.

90. Dooley, H., Flajnik, M. F., \& Porter, A. J. (2003). Selection and characterization of naturally occurring single-domain (IgNAR) antibody fragments from immunized sharks by phage display. Molecular Immunology, 40, 25-33.

91. Zielonka, S., Ampting, M., Grzeschik, J., Könning, D., Barelle, C. J., \& Kolmar, H. (2015). Structural insights and biomedical potential of IgNAR scaffolds from sharks. $m A b s, 7,15-25$.

92. Nuttall, S. D., Krishnan, U. V., Hattarki, M. De, Gori, R., Irving, R. A., \& Hudson, P. J. (2001). Isolation of a new antigen receptor from wobbegong sharks, and use as a scaffold for the display of protein loop libraries. Molecular Immunology, 38, 313-326.

93. Nuttall, S. D., Krishnan, U. V., Hattarki, Doughty, Nathanielsz, L., Ally, A., Pike, N., et al. (2002). A naturally occurring NAR variable domain binds the Kgp protease from Porphyrmonas gingivalis. FEBS Letters, 516, 80-86.

94. Goodchild, S. A., Dooley, H., Schoepp, R. J., Flajnik, M., \& Lonsdale, S. G. (2011). Isolation and characterisation of Ebolavirusspecific recombinant antibody fragments from murine and shark immune libraries. Molecular Immunology, 48, 2027-2037.

95. Leow, C. H., Fischer, K., Leow, C. Y., Braet, K., Cheng, Q., \& McCarthy, J. (2018). Isolation and characterization of malaria PfHRP2 specific $V_{N A R}$ antibody fragments from immunized shark phage display library. Malaria Journal, 17, 383.

96. Liu, J. L., Anderson, G. P., Delehanty, J. B., Baumann, R., Hayhurst, A., \& Goldman, E. R. (2007). Selection of cholera toxin specific IgNAR single-domain antibodies from a naïve shark library. Molecular Immunology, 44, 1775-1783.

97. Ohtani, M., Hikima, J., Jung, T. S., Kondo, H., Hirono, I., \& Aoki, T. (2013). Construction of an artificially randomized IgNAR phage display library: Screening of variable region that bind to hen white lysozyme. Marine Biotechnology, 15, 56-62.

98. Zadeh, A. S., Grässer, A., Dinter, H., Hermes, M., \& Schindowski, K. (2019). Efficient onstruction and effective screening of synthetic domain antibody libraries. Methods and Protocols, 2,17 .

99. Kovaleva, M., Johnson, K., Steven, J., Barelle, C. J., \& Porter, A. (2017). Therpaeutic potetnia of shark anti-ICOSL $\mathrm{V}_{\mathrm{NAR}}$ domains is exemplified in a murine model of autoimmune non-infectious uveitis. Frontiers in Immunology, 8, 1121.

100. Hattori, T., Lai, D., Dementieva, I. S., Montaño, S. P., Kurosawa, K., Zheng, Y., et al. (2016). Antigen clasping by two antigenbinding sites of an exceptionally specific antibody for histone methylation. Proceedings of the National Academy of Sciences USA, 113, 2092-2097.

101. Henry, K. A., Tanha, J., \& Hussack, G. (2015). Identification of cross-reactive single-domain antibodies against serum albumin using next-generation DNA sequencing. Protein Engineering, Design \& Selection, 28, 379-383.

102. Skottrup, P. D., Leonard, P., Kaczmarek, J. Z., Veillard, F., Enghild, J. J., O'Kennedy, R., et al. (2011). Diagnostic evaluation of a nanobody with picomolar affinity toward the protease RgpB from Porphyromonas gingivalis. Analytical Biochemistry, 415, $158-167$.

Publisher's Note Springer Nature remains neutral with regard to jurisdictional claims in published maps and institutional affiliations. 